$\xi=$

\title{
A comparative study on feature extraction and classification of mind waves for brain computer interface (BCI)
}

\author{
Manjula. $\mathrm{K}^{1 *}$, M.B. Anandaraju ${ }^{2}$ \\ ${ }^{1}$ Asst. professor, Dept of TCE, S.J.C.I.T, Chickballapur, India \\ ${ }^{2}$ Professor \& HOD, Dept of ECE, B.G.S.I.T, B. G. Nagar, India \\ *Corresponding author E-mail: manjula.bhagyakrishna@gmail.com
}

\begin{abstract}
Brain Computer Interfacing (BCI) is a methodology which imparts a path for communication from external world using brain signals through computer. BCI identifies the specific patterns in a person's changing brain activity to initiate control which relates to the person's intention. The BCI system paraphrases these signal patterns into meaningful control command. In evolving BCI system, numerous signal processing algorithms are proposed. Non-invasive Electroencephalogram (EEG) signals or mind waves are used to extract the distinguished features and further they are classified choosing an appropriate classifier. A study on different feature extraction \& Classification algorithms is used in EEG-based BCI exploration and to identify their distinct properties. This paper proposes different methodologies of feature extraction and feature Classification. It also addresses the methods and technology adapted in every phase of the EEG signal processing. This comparative survey also helps in selecting suitable algorithm for the development and accomplishment of further classification of signals.
\end{abstract}

Keywords: Brain Computer Interface (BCI); Electroencephalogram (EEG); Feature Extraction; Feature Classification; Central Nervous System (CNS); Wavelet Transforms (WT).

\section{Introduction}

Electroencephalogram (EEG) has a time series data of summon potentials which results from the neural activities in a brain. The data acquisition of the human mind waves (EEGs) are collected from the electrodes [1] situated directly on the grey matter or upon the scalp which are called as Invasive and Non-invasive methods and that electrical activity between neurons known as voltage magnitude is plotted versus time. The electrical activity of the EEG signal is nothing but the amplitude of EEG signal. The two different types of cells in the Central Nervous System (CNS) are nerve cells and glia cells. The axons, dendrites and cell bodies form the nerve cell as shown in figure 1. The electrical impulse is transmitted by axon which is cylindrical in shape whereas; to the other side of axon, dendrites are connected and which receives the electrical fluctuation from other nerves cells. Humans each nerve is approximately connected to 10000 other nerve cells [2]. The electrical activity between neurons is mainly because of the current flow between the dendrites tip and axons, dendrites and dendrites of cells. These signals level is at $\mathrm{V}$ range and of frequency is less than $100 \mathrm{~Hz}[2]$.

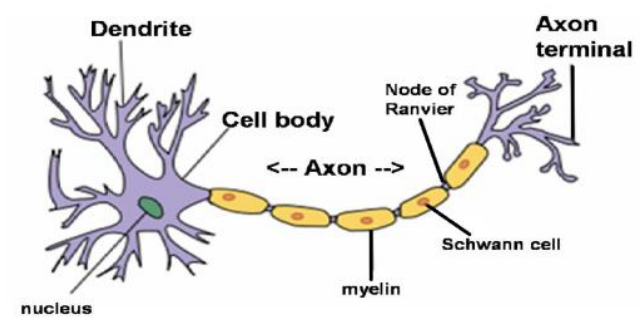

Fig. 1: Structure of a Neuron [5].
The voltage level of the non-invasive EEG ranges between $10 \mathrm{~V}$ and $100 \mu \mathrm{V}$, whereas in adults approximately in the range of $10 \mathrm{~V}$ to $50 \mu \mathrm{V}$. In the clinical EEG the very high frequency ranges play no significant role. The interested general frequency range lies between $0.1 \mathrm{~Hz}$ and $100 \mathrm{~Hz}$ for the classification purpose[3]. The frequency range of EEG signal is basically classified into several frequency ranges, namely delta rhythm, theta rhythm, alpha rhythm and beta rhythm based on their frequency range which is illustrated in Table1.

Table 1: Different EEG Bands

\begin{tabular}{|c|c|c|c|}
\hline $\begin{array}{l}\text { EEG Fre- } \\
\text { quency band }\end{array}$ & $\begin{array}{l}\text { Frequency } \\
\text { range }\end{array}$ & Location & Signal Condition \\
\hline Delta & $0.5-4 \mathrm{~Hz}$ & Frontal Lobe & $\begin{array}{l}\text { Most apparent in deep } \\
\text { sleep states }\end{array}$ \\
\hline Theta & $4-8 \mathrm{~Hz}$ & $\begin{array}{l}\text { Temporal and } \\
\text { Parietal }\end{array}$ & $\begin{array}{l}\text { Appear in relaxed state, } \\
\text { light sleep \& Medita- } \\
\text { tion }\end{array}$ \\
\hline Alpha & $8-12 \mathrm{~Hz}$ & Occipital & $\begin{array}{l}\text { Associated with medi- } \\
\text { tation \& relaxation }\end{array}$ \\
\hline Beta & $13-30 \mathrm{~Hz}$ & $\begin{array}{l}\text { Frontal } \\
\text { Central }\end{array}$ & $\begin{array}{l}\text { Connected to alertness } \\
\& \text { focus }\end{array}$ \\
\hline Gamma & $>30 \mathrm{~Hz}$ & Parietal Lobe & Subjective awareness \\
\hline
\end{tabular}

\section{EEG signal analysis}

Human brain consists of millions of interconnected neurons. This neuron pattern will change according to human thoughts and at each pattern formation unique electric brain signal will form. EEG carries important information on the responses to stimuli in the human brain. From the pattern of the brain signal waveforms, one 
can identify the emotion types of e up to a certain level of accuracy. An emotion recognition system will help in understanding the cognitive functions of the brain. This can also enable and control of machines such as the cursor of a computer, wheelchairs, or a robotic arm. It may even allow disabled patients who have lost their voice and movement ability to express their thoughts and emotions. These brain signals are analyzed at three different stages namely

i) Signal Acquisition module

ii) Signal processing Module.

iii) Control module

The block diagram of EEG signal Analysis is shown in figure 2.

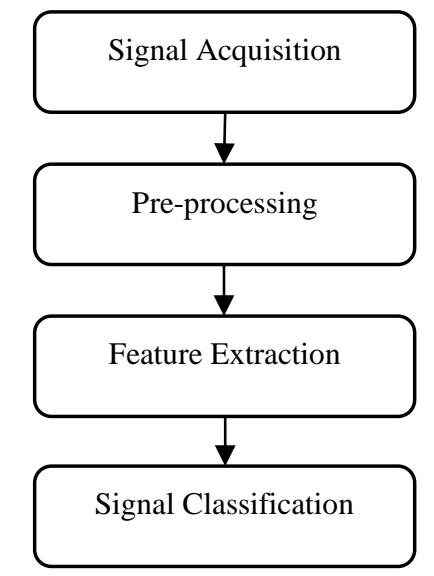

Fig. 2: Flow Chart of EEG Signal Analysis.

In the Pre-processing stage the acquired signal is processed to remove the artifacts, the signal is averaged and the threshold of the output signal is set this stage will also takes care of the enhancement of the resulting signal. The step followed by pre-processing is feature extraction, where feature means distinctive measure from a segment of a pattern. Feature extraction module is responsible for choosing the features which is most important for classification. Signal Classification is the final state solved by linear analysis, non-linear analysis, adaptive algorithms, clustering techniques, fuzzy techniques \& neural networks

\section{Types of signal acquisition for BCI}

For acquisition of the brain signals in BCI, there are invasive, Partially Invasive and non-invasive methods as shown in figure 3. Electrocorticogram (ECoG), Electrosubcorticogram (ESCoG), and Electroventriculogram (EVG) are typical invasive measurement methods where the electrodes are implanted directly on to the skull. They need surgeries for installing electrodes on a cortex or a cerebral ventricle and measure electrical activities of brain neurons. The invasive methods can measure the brain activities with noise much less than that in the non-invasive methods with good resolution. On the other hand, the non-invasive methods do not require such medical surgeries.

The partially invasive methods are considered as lower risk of forming tissue as comparing with invasive techniques where electrodes are implanted inside the skull which produces better resolution signals.

The non-invasive methods are considered that they impose a less load on subject and are more practical methods for realizing BCIs than the invasive and partially invasive methods. Noninvasively measured data such as electroencephalogram (EEG), magnetoencephalogram (MEG) [4], and functional Magnetic Resonance Imaging (fMRI), and near-infrared spectroscopy are commonly used to the BCI research work. Non-invasive methods comparatively produce poor signals.

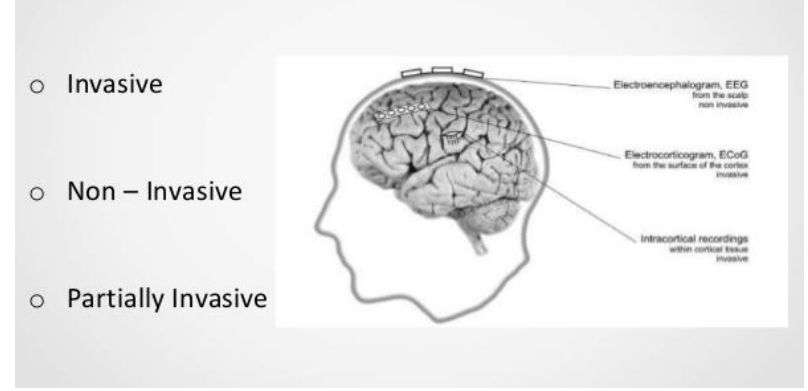

Fig. 3: Different Methods for Signal Acquisition in BCI.

Among all the three methods, because of its simplicity and low cost, EEG is practical for use in engineering applications. Moreover, EEG can achieve higher temporal resolution than the other invasive methods [5].

EEG is recorded from many electrodes arranged in a particular pattern. More prominently a common standard called the International 10/20 System as shown in figure 4 is used. These methods are low-priced and give a relentless record of brain activity with better than millisecond resolution. This tool can achieve the high temporal resolution and for this reasons the detailed discoveries of dynamic cognitive processes have been reported using EEG and ERP (Event Related Potentials) methods [6].

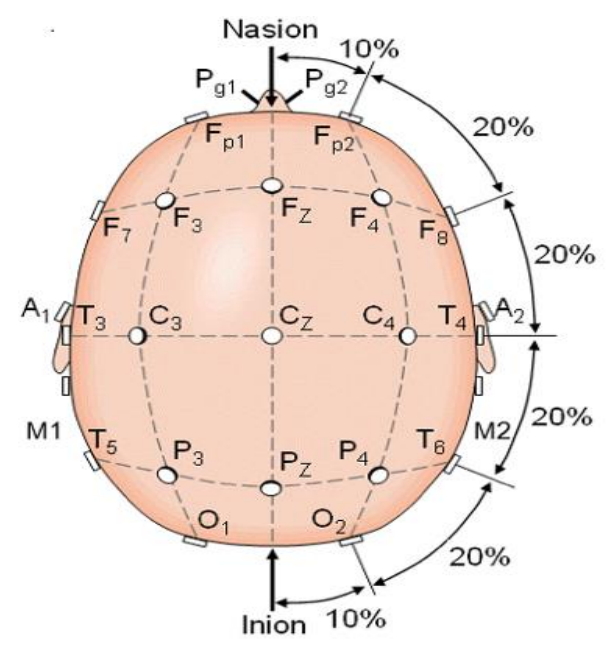

Fig. 4: 10/20 Electrode Positioning System [6].

Electrode placements are proportional to size of the skull \& and its shape. There are main 4 skull landmarks namely Nasion, Inion, Left Pre-auricular point and Right Pre-auricular point. The electrode placement is shown in the figure and measurements are as specified in Table 2.

Table 2: Different Electrodes Positioning According to International Standard 10-20 System

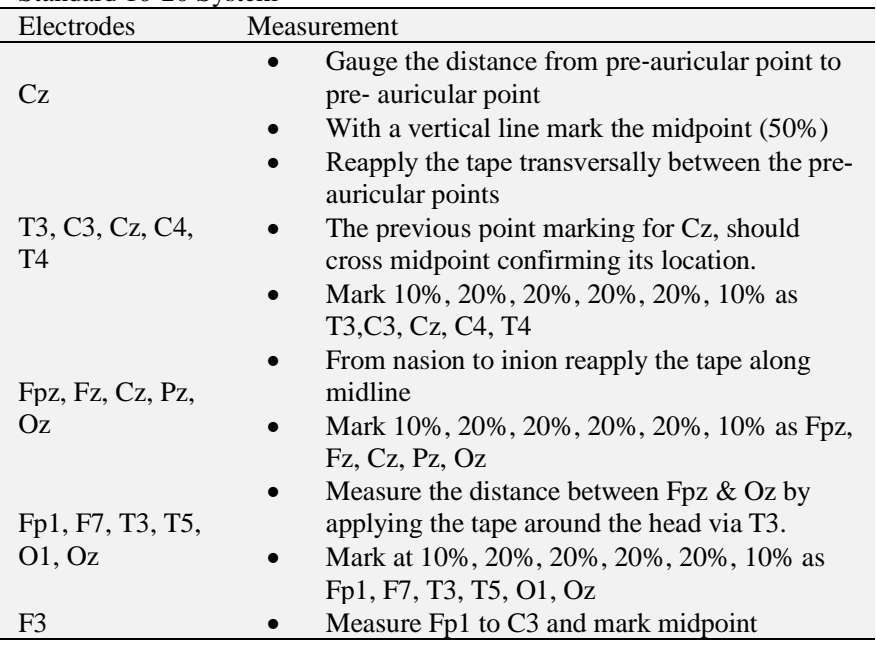


- $\quad$ Measure Fz to F7 and mark midpoint

- Mark $50 \%=\mathrm{F} 3$

- The reference electrodes are M1 \& M2 (formally known as A1 \& A2)

M1 \& M2

- $\quad$ M1 \& M2 are placed on the mastoid (M) process.

\section{Feature extraction methods}

EEG signals are non-stationary that is, its spectrum changes with time so we have to adopt different feature extraction methods. The different feature extraction methods are Log variance method, Power density Estimation, Wavelet packet decomposition, Autoregressive modelling, Hibert Huang Transform, Principal Component Analysis, Independent Component Analysis, FFT, Local Discriminant Bases, Shift-Invariant LDB, Morphological LDB (MLDB), DFT \& STFT. The different feature Extraction methods are discussed below, to analyse and choose the best Feature Extraction method in our Research.

a) Wavelet transform: Wavelet transforms (WT) analyze various fluctuating events in biomedical field. Comparing WT with spectral analysis, WT is more advantageous and WT is also suitable for nonstationary signals. Wavelet is an effective method for Time frequency representation of a signal. The important advantage of Wavelet transform is that at low frequencies it provides accurate frequency information and accurate time information at the high frequencies. In biomedical applications this property plays a prominent role. Because most signals in the biomedical field always contain high frequency components with short time period and low frequency components with long time period. For nonstationary signals WT provides multiresolution analysis.

b) Autoregressive Modeling: Autoregressive model (AR) is feature extraction technique for classification of writing task from EEG signal. Assumed writing task gives useful information that is used in improving the writing disorders. AR model extends its usage in application of imagined letters classification from EEG signal. AR model is also used in mental tasks detection using neural network and it provides 91\% accuracy. The EEG signal changes in its voltage as well as frequency while different mental tasks are performed. Hence these features can be captured and extracted using modeling techniques, such as autoregressive models. AR model is combination of ICA and past EEG which brings the present EEG samples which is widely used in EEG analysis. The basic idea of autoregressive (AR) model is that assuming the real EEG is approximated by AR process.

c) Fast Fourier Transform (FFT): The FFT is an efficient tool for the feature extraction. FFT algorithm is involved a wide range of mathematical operation from simple real and complex numbers arithmetic to group data set analysis. The calculation in DFT is very complex and time consuming to reduce the operation time and increasing the speed by using FFT. They are used in a wide range of applications, ranging from solution of partial differential equations, digital signal processing and to algorithms for large integer numbers multiplication using different algorithms of FFT and filters for increased speed.

\section{Feature classification methods}

To recognize different EEG signals the selected features from feature extraction should be classified.For EEG classification various classifiers are used, and they can be divided into five categories, namely, linear classifiers, neural networks, nonlinear Bayesian classifiers, nearest neighbour classifiers, and combinations of classifiers. Li et al. [8] used a support vector machine (SVM) for multiple kernel learning to classify EEG signals. Zou et al. [9] classified EEG signals by Fisher linear discriminant analysis
(LDA). Djemili et al. [10] fed the feature vector to a multilayer perceptron (MLP) neural network classifier. Beacause the classification capacity of a single classification method is limited, so many researchers have tried to combine two or more methods to improve classification accuracy. For example, Subasi et al. [11] adopted an artificial neural network (ANN) and logistic regression to classify EEG signals. Wang et al. [12] combined crossvalidation $(\mathrm{CV})$ with $\mathrm{k}$-nearest neighbor $(\mathrm{k}-\mathrm{NN})$ to construct a hierarchical knowledge base to detect epilepsy. Murugavel et al. [13] also proposed a novel hierarchical multi-class SVM, with extreme learning machine as kernel, to classify EEG signals. For improvement in the accuracy of epilepsy detection researchers have also studied the application of machine learning and optimization algorithms. Amin et al. [14] compared the classification accuracy rate of SVM, MLP, k-NN, and Naïve Bayes (NB) classifiers for epilepsy detection. Nunes et al. [15] used the optimum path forest classifier for seizure identification. Moreover, artificial bee colony [16] and particle swarm optimization [17] algorithms were also used to optimize neural networks for EEG data classification. [7] proposed a novel method for secure transportation of railway systems has been proposed in this project. In existing methods, most of the methods are manual resulting in a lot of human errors. This project proposes a system which can be controlled automatically without any outside help. This project has a model concerning two train sections and a gate section. The railway sections are used to show the movement of trains and a gate section is used to show the happenings in the railway crossings. The scope of this project is to monitor the train sections to prevent collisions between two trains or between humans and trains and to avoid accidents in the railway crossings. Also an additional approach towards effective power utilization has been discussed. Five topics are discussed in this project: 1) Detection of obstacles in front of the train; 2) Detection of cracks and movements in the tracks; 3) Detection of human presence inside the train and controlling the electrical devices accordingly 4) Updating the location of train and sharing it with other trains automatically 5) Controlling the gate section during railway crossing. This project can be used to avoid accidents in the railway tracks.

Few Classification methods are discussed below

a) K-Nearest Neighbor (KNN): K-nearest neighbor is an occurance-based and supervised learning algorithm which is a very easy for implementation. KNN algorithm stores all the available cases and new cases been classified depending on a similarity measure. $\mathrm{KNN}$ is a non-parametric method which classifies the based on the estimation of featured values which is possible by comparing the training data with testing data [18]. These feature values are calculated from the distance function such as Euclidean distance which is a easy method, if the numeric parameter values are given. By the majority vote of its neighbours an object is classified. Considering the class which is most common with its $\mathrm{k}$ nearest neighbours the object will be assigned. The value of the $\mathrm{k}$ indicates how many nearest values has to be be considered for the output class decision.

b) Linear Discriminant Analysis (LDA) For BCI applications, linear discriminant analysis (LDA) is one of the most accepted classification algorithms. LDA classifies a set of observations into predetermined classes. Linear transformation of data from higher dimensional space to lower dimensional space is achieved by LDA. Finally, the decision is made in the low dimensional space. Thus defining a decision boundary makes a major role in classification process. The distributions of class with some finite variance are retained in the intended space during process. Hence, we presume that for calculation of decision boundary the mean and standard variance of the intended data is considered.

c) Naive Bayes Probability: It can be interpreted from two views-Objective and Subjective. The Bayesian Probability is the Subjective probability. Bayesian Probability is the method of probability which assumes certain futuristic events. Naive Bayes is a conditional probability model 
where Bayes' theorem is used to infer the probability of hypothesis under the observed data or evidence.

Bayes theorem states that posterior $=\frac{\text { prior } * \text { likelihood }}{\text { Evidence }}$

$P(B \mid A)=\frac{P(A \mid B) P(B)}{P(A)}$

d) Neural Networks: The Neural Networks (NN), is composed through linear classifiers, the grouping of classifiers typically castoff in BCI set up. Multilayer Perception, is the greatest extensively castoff NN for BCI. An MLP is collected of numerous coats of neurons; an involvement layer, conceivably one or quite a lot of unseen layers, and an amount produced layer [20]. Neural Networks and consequently MLP are widespread estimates. Further to the circumstance, they can categorize any amount of sessions; this creates NN actual supple classifiers that can get used to a countless diversity of difficulties. [19] Discussed about a method, Sensor network consists of low cost battery powered nodes which is limited in power. Hence power efficient methods are needed for data gathering and aggregation in order to achieve prolonged network life. However, there are several energy efficient routing protocols in the literature; quiet of them are centralized approaches, that is low energy conservation. This paper presents a new energy efficient routing scheme for data gathering that combine the property of minimum spanning tree and shortest path tree-based on routing schemes. The efficient routing approach used here is Localized Power-Efficient Data Aggregation Protocols (LPEDAPs) which is robust and localized. This is based on powerful localized structure, local minimum spanning tree (LMST). The actual routing tree is constructed over this topology. There is also a solution involved for route maintenance procedures that will be executed when a sensor node fails or a new node is added to the network.

\section{Comparison of feature extraction tech- niques}

Table 3: Comparison of WT, AR, FFT Feature Extraction Methods

\begin{tabular}{|c|c|c|c|c|c|}
\hline 1 & $\begin{array}{l}\text { Wavelet trans- } \\
\text { form }\end{array}$ & 1) & $\begin{array}{l}\text { Signal with dis- } \\
\text { continuities is } \\
\text { analyzed by } \\
\text { WT with differ- } \\
\text { ent window size } \\
\text { Signal is ana- } \\
\text { lyzed in both } \\
\text { time and fre- } \\
\text { quency domain } \\
\text { Suited for tran- } \\
\text { sient changes }\end{array}$ & 2) & $\begin{array}{l}\text { Appropriate } \\
\text { mother wavelet } \\
\text { must be chosen } \\
\text { Uncertainty re- } \\
\text { duces its perfor- } \\
\text { mance }\end{array}$ \\
\hline 2 & $\begin{array}{l}\text { Autoregressive } \\
\text { Modeling }\end{array}$ & 1) & $\begin{array}{l}\text { Recording peri- } \\
\text { od is short } \\
\text { Provides better } \\
\text { frequency reso- } \\
\text { lution } \\
\text { Reduces spec- } \\
\text { tral losses }\end{array}$ & 2) & $\begin{array}{l}\text { Developing } \\
\text { model properties } \\
\text { is complicated } \\
\text { Incorrect model } \\
\text { selection leads to } \\
\text { poor resolution }\end{array}$ \\
\hline 3 & $\begin{array}{l}\text { Fast Fourier } \\
\text { Transform }\end{array}$ & 2) & $\begin{array}{l}\text { Good tool for } \\
\text { stationary sig- } \\
\text { nals } \\
\text { Enhanced speed } \\
\text { over virtually } \\
\text { other methods }\end{array}$ & 2) & $\begin{array}{l}\text { Suffers from } \\
\text { large noise sensi- } \\
\text { tivity } \\
\text { Time localization } \\
\text { is poor }\end{array}$ \\
\hline
\end{tabular}

Table 3 shows comparison of wavelet transform, Autoregressive Modeling and Fast Fourier Transform with their positive features and drawbacks which helps us to analyze the different feature extraction methods and to select correct classifier to get better accuracy.

\section{Comparison of feature classification meth- ods}

Table 4: Comparison of KNN, LDA, NBP, NN Feature Classification Methods

\begin{tabular}{|c|c|c|c|c|c|}
\hline 1 & $\begin{array}{l}\text { K-Nearest } \\
\text { Neighbor } \\
(\text { KNN) }\end{array}$ & 2) & $\begin{array}{l}\text { Understanding } \\
\text { algorithm is easy } \\
\text { Implementation is } \\
\text { also easy }\end{array}$ & 1) & $\begin{array}{l}\text { Runtime perfor- } \\
\text { mance is not upto } \\
\text { the mark } \\
\text { Sensitive to noise }\end{array}$ \\
\hline 2 & $\begin{array}{l}\text { Linear Dis- } \\
\text { criminant } \\
\text { Analysis }\end{array}$ & $\begin{array}{l}\text { 2) } \\
\text { 3) }\end{array}$ & $\begin{array}{l}\text { Computational } \\
\text { requirement is } \\
\text { low } \\
\text { Simple to use } \\
\text { Gives accurate } \\
\text { results }\end{array}$ & 1) & $\begin{array}{l}\text { Discrimination } \\
\text { function should } \\
\text { be mean not vari- } \\
\text { ance } \\
\text { It correctly works } \\
\text { for only Gaussian } \\
\text { distribution }\end{array}$ \\
\hline 3 & $\begin{array}{l}\text { Naïve Bayes } \\
\text { Probability }\end{array}$ & 2) & $\begin{array}{l}\text { Conditional prob- } \\
\text { ability model } \\
\text { Implementation is } \\
\text { easy } \\
\text { Independent pair } \\
\text { of features and } \\
\text { fast }\end{array}$ & 1) & Less accurate \\
\hline 4 & $\begin{array}{l}\text { Neural Net- } \\
\text { works }\end{array}$ & $\begin{array}{l}\text { 1) } \\
\text { 2) }\end{array}$ & $\begin{array}{l}\text { Pattern classifica- } \\
\text { tion is accurate } \\
\text { Training is easy }\end{array}$ & 1) & $\begin{array}{l}\text { For large network } \\
\text { processing time } \\
\text { required is more }\end{array}$ \\
\hline
\end{tabular}

Table 4 shows comparison of K-Nearest Neighbour (KNN), Linear Discriminant Analysis (LDA), Naïve Bayes Probability and Neural Networks with their positive features and drawbacks which helps us to understand various classification methods.

\section{Conclusion}

This Review paper gives a clear analysis of different Feature Extraction methods and Classification methods in Brain Computer Interface, which can be used for the detection of human emotions and to select the best algorithm. Researchers will extemporize the efficiency and accuracy in deciding the appropriate method which can be used in signal Classification. The variations are identified by EEG signal with various feature extraction techniques and classification methods. The emotions accuracy may be different from one extract technique to another. The combination of different extraction techniques with the classification method provides better results. This better accuracy level and less error rate is used to analyse which method is suitable to classify the emotions in different class of people.

\section{References}

[1] Teplan, M. 2002. Fundamentals of EEG Measurement. Measurement Science Review. 2(2).

[2] R. Leeb, D. Friedman, G. R. M“uller-Putz, R. Scherer, M. Slater, andG. Pfurtscheller, "Self-paced (asynchronous) BCI control of a wheelchair in virtual environments: a case study with a tetraplegic," Computational Intelligence and Neuroscience, vol. 2007, pp. 7:17:12, 2007

[3] E. Niedermeyer, "Epileptic seizure disorders" Chapter 27, in E. Niedermeyer and F.L. da Silva ed. "Electroencephalography: Basic principles, Clinical applications, and Related fields", Fourth edition. Lippincott Willams \& Wilkins, Philadelphia (1999).

[4] Saeid Sanei and J.A. Chambers, EEG Signal Processing, John Wiley and Sons Ltd, England, 2007.

[5] Mandeep Singh, Mooninder Singh and Surabhi Gangwar "Emotion Detection Using Electroencephalography (EEG): A Review", International Journal of Information Technology \& Knowledge Management. Vol.7 no.1 Dec.2013

[6] Niels Birbaumer "Breaking the silence: Brain-computer interfaces (BCI) for communication and motor control" Psychophysiology, 2006, https://doi.org/10.1111/j.1469-8986.2006.00456.x.

[7] Christo Ananth, K.Nagarajan, Vinod Kumar.V., "A SMART APPROACH FOR SECURE CONTROL OF RAILWAY TRANSPORTATION SYSTEMS", International Journal of Pure and Applied Mathematics, Volume 117, Issue 15, 2017, (1215-1221). 
[8] Li, X., Chen, X., Yan, Y., Wei, W., \& Wang, Z. J. (2014). Classification of eeg signals using a multiple kernel learning support vector machine. Sensors, 14(7), 12784-12802. https://doi.org/10.3390/s140712784.

[9] Zou, L., Wang, X., Shi, G., \& Ma, Z. (2010). EEG feature extraction and pattern classification based on motor imagery in braincomputer interface. IEEE International Conference on Cognitive Informatics (pp.536-541). IEEE. https://doi.org/10.1109/COGINF.2010.5599682.

[10] Djemili, R., Bourouba, H., \& Korba, M. C. A. (2015). Application of empirical mode decomposition and artificial neural network for the classification of normal and epileptic eeg signals. Biocybernetics \& Biomedical Engineering, 36(1), 285-291. https://doi.org/10.1016/j.bbe.2015.10.006.

[11] Subasi, A., \& Erçelebi, E. (2005). Classification of eeg signals using neural network and logistic regression. Computer Methods \& Programs in Biomedicine, 78(2), 87-99. https://doi.org/10.1016/j.cmpb.2004.10.009.

[12] Wang, D., Miao, D., \& Xie, C. (2011). Best basis-based wavele packet entropy feature extraction and hierarchical eeg classification for epileptic detection. Expert Systems with Applications, 38(11), 14314-14320. https://doi.org/10.1016/j.eswa.2011.05.096.

[13] Murugavel, A. S. M., \& Ramakrishnan, S. (2016). Hierarchical multi-class svm with elm kernel for epileptic eeg signal classification. Medical \& Biological Engineering \& Computing, 54(1), 149 161. https://doi.org/10.1007/s11517-015-1351-2.

[14] Amin, H. U., Malik, A. S., Ahmad, R. F., Badruddin, N., Kamel, N., \& Hussain, M., et al. (2015). Feature extraction and classification for eeg signals using wavelet transform and machine learning techniques. Australasian Physical \& Engineering Sciences in Medicine, 38(1), 1-11. https://doi.org/10.1007/s13246-015-0333-x.

[15] Nunes, T. M., Coelho, A. L. V., Lima, C. A. M., Papa, J. P., \& Albuquerque, V. H. C. D. (2014). Eeg signal classification for epilepsy diagnosis via optimum path forest - a systematic assessment Neurocomputing, 136(1), 103-123.16 https://doi.org/10.1016/j.neucom.2014.01.020.

[16] Satapathy, S. K., Dehuri, S., \& Jagadev, A. K. (2016). Abc optimized rbf network for classification of eeg signal for epileptic seizure identification. Egyptian Informatics Journal.

[17] Lin, C. J., \& Hsieh, M. H. (2009). Classification of mental task from eeg data using neural networks based on particle swarm optimization. Neurocomputing, 72(4-6), 1121-1130. https://doi.org/10.1016/j.neucom.2008.02.017.

[18] Tatiur Rahman, Apu Kumer Ghosh, Md. Maruf Hossain Shuvo, Md. Mostafizur Rahman, "Mental Stress Recognition using K-Neares Neighbor(KNN) Classifier on EEG Signals", International Conference on Materials, Electronics \& Information Engineering, ICMEIE-2015.

[19] Christo Ananth, S.Mathu Muhila, N.Priyadharshini, G.Sudha P.Venkateswari, H.Vishali, "A New Energy Efficient Routing Scheme for Data Gathering “,International Journal Of Advanced Research Trends In Engineering And Technology (IJARTET), Vol. 2, Issue 10, October 2015), pp: 1-4

[20] Chiappa, S., \& Bengio, S. (2004, April). HMM and IOHMM modeling of EEG rhythms for asynchronous BCI systems. In European Symposium on Artificial Neural Networks, ESANN (pp. 193-204).

[21] J. Preethi, M.Sreeshakthy, A.Dhilipan, "A Survey on EEG Based Emotion Analysis using various Feature Extraction Techniques", International Journal of Science, Engineering and Technology Research (IJSETR), Department of Computer Science, Anna University Regional Centre, Volume 3, Issue 11, November 2014

[22] M. Ungureanu, C. Bigan, R. Strungaru, V. Lazarescu, "Independent Component Analysis Applied in Biomedical Signal Processing," Measurement Science Review, vol. 4, section 2, 2004. 